Table 1. Multivariate analysis of clinical characteristics/outcomes \& WPAI domains at W0 \& W24

\begin{tabular}{|c|c|c|c|c|c|c|c|c|}
\hline \multirow[t]{2}{*}{ Parameter } & \multicolumn{2}{|c|}{ Absenteeism $^{a}$} & \multicolumn{2}{|c|}{ Presenteeism ${ }^{a}$} & \multicolumn{2}{|c|}{$\begin{array}{l}\text { Productivity } \\
\text { Loss }^{\text {a }}\end{array}$} & \multicolumn{2}{|c|}{$\begin{array}{l}\text { Activity } \\
\text { Impairment }^{\mathrm{b}}\end{array}$} \\
\hline & Estimate & $\mathrm{p}$-value & Estimate & $\mathrm{p}$-value & Estimate & $\mathrm{p}$-value & Estimate & $\mathrm{p}$-value \\
\hline Age & -0.05 & 0.42 & -0.27 & $<0.001$ & -0.28 & $<0.001$ & -0.06 & 0.17 \\
\hline Female & 0.91 & 0.46 & -1.54 & 0.22 & -1.74 & 0.20 & 2.38 & 0.02 \\
\hline CRP & 0.73 & 0.04 & 0.97 & 0.01 & 1.01 & 0.01 & 0.89 & $<0.001$ \\
\hline FACIT-F & -0.31 & $<0.001$ & -0.67 & $<0.001$ & -0.73 & $<0.001$ & -0.75 & $<0.001$ \\
\hline Pain & 1.03 & $<0.001$ & 4.15 & $<0.001$ & 4.25 & $<0.001$ & 4.02 & $<0.001$ \\
\hline PASI & 0.06 & 0.36 & 0.16 & 0.02 & 0.14 & 0.05 & 0.15 & 0.003 \\
\hline SJC & 0.08 & 0.48 & -0.05 & 0.61 & -0.05 & 0.66 & 0.03 & 0.75 \\
\hline TJC & -0.10 & 0.13 & 0.11 & 0.09 & 0.09 & 0.19 & 0.10 & 0.04 \\
\hline Dactylitis $(\mathrm{Y} / \mathrm{N})$ & -1.10 & 0.39 & 2.47 & 0.05 & 2.58 & 0.05 & 0.54 & 0.57 \\
\hline Enthesitis $(\mathrm{Y} / \mathrm{N})$ & 1.52 & 0.20 & 2.38 & 0.04 & 2.99 & 0.01 & 2.40 & 0.01 \\
\hline
\end{tabular}

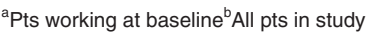

Disclosure of Interests: Jeffrey Curtis Consultant of: AbbVie, Amgen, Bristol-Myers Squibb, Corrona, Janssen, Eli Lilly, Myriad, Pfizer, Regeneron, Roche, and UCB, Grant/research support from: AbbVie, Amgen, Bristol-Myers Squibb, Corrona, Janssen, Eli Lilly, Myriad, Pfizer, Regeneron, Roche, and UCB, lain McInnes Consultant of: AbbVie, Bristol-Myers Squibb, Celgene, Eli Lilly, Gilead, Janssen, Novartis, Pfizer, and UCB, Grant/research support from: Bristol-Myers Squibb, Celgene, Eli Lilly, Janssen, and UCB, Dafna D Gladman Consultant of: AbbVie, Amgen, Bristol Myers Squibb, Eli Lilly, Galapagos, Gilead, Janssen, Novartis, Pfizer and UCB, Grant/research support from: AbbVie, Amgen, Bristol Myers Squibb, Eli Lilly, Galapagos, Gilead, Janssen, Novartis, Pfizer and UCB, Feifei Yang Shareholder of: Janssen, Employee of: Janssen, Steve Peterson Shareholder of: Janssen, Employee of: Janssen, Prasheen Agarwal Shareholder of: Janssen, Employee of: Janssen, Alexa Kollmeier Shareholder of: Janssen, Employee of: Janssen, Elizabeth C Hsia Shareholder of: Janssen, Employee of: Janssen, Chenglong Han Shareholder of: Janssen, Employee of: Janssen, May Shawi Shareholder of: Janssen, Employee of: Janssen, William Tillett Speakers bureau: AbbVie, Amgen, Celgene, Eli Lilly, Janssen, Novartis, Pfizer, and UCB, Consultant of: AbbVie, Amgen, Celgene, Eli Lilly, Janssen, Novartis, MSD, Pfizer, and UCB, Grant/research support from: AbbVie, Celgene, Eli Lilly, Janssen, and Novartis, Philip J Mease Consultant of: AbbVie, Amgen, Boehringer Ingelheim, Bristol Myers Squibb, Eli Lilly, Galapagos, Gilead, GlaxoSmithKline, Janssen, Novartis, Pfizer, SUN, and UCB, Grant/research support from: AbbVie, Amgen, Bristol Myers Squibb, Eli Lilly, Galapagos, Gilead, Janssen, Novartis, Pfizer, SUN, and UCB, Proton Rahman Speakers bureau: AbbVie, Amgen, Bristol Myers Squibb, Celgene, Eli Lilly, Janssen, Novartis, Pfizer, Roche, and UCB, Consultant of: AbbVie, Amgen, Bristol Myers Squibb, Celgene, Eli Lilly, Janssen, Novartis, Pfizer, Roche, and UCB, Grant/research support from: Janssen and Novartis DOI: 10.1136/annrheumdis-2021-eular.274

\section{POS0201 RISK OF MAJOR ADVERSE CARDIOVASCULAR EVENTS IN PATIENTS INITIATING BIOLOGICS/ APREMILAST FOR PSORIATIC ARTHRITIS: A NATIONWIDE POPULATION-BASED STUDY USING THE FRENCH HEALTH INSURANCE DATABASE}

L. Pina Vegas $^{1,2}$, P. Le Corvoisier ${ }^{3,4}$, L. Penso ${ }^{1,5}$, M. Paul ${ }^{1,6}$, E. Sbidian ${ }^{1,4,7}$, P. Claudepierre ${ }^{1,2} .{ }^{1}$ Université Paris Est-Créteil, EpiDermE, Créteil, France; ${ }^{2} \mathrm{Hôpital}$ Henri Mondor, Rhumatologie, Créteil, France; ${ }^{3}$ Inserm, Université Paris Est-Créteil, Ecole Nationale Vétérinaire d'Alfort, U955-IMRB, Équipe 03, Créteil, France; ${ }^{4}$ Inserm, Hôpital Henri Mondor, Centre D'investigation Clinique 1430, Créteil, France; ${ }^{5}$ French National Agency for the Safety of Medicines and Health Products and French National Health Insurance, EPI-PHARE Scientific Interest Group in Epidemiology of Health Products, Saint-Denis, France; ${ }^{6} \mathrm{Hop}$ ital Henri Mondor, Pharmacie, Créteil, France; ${ }^{7}$ Hôpital Henri Mondor, Dermatologie, Créteil, France

Background: Psoriatic arthritis (PsA) is associated with other diseases of the spectrum of spondyloarthritis but also appears to be linked to an increased prevalence of numerous comorbidities and more specifically cardiovascular risk factors and events. Several biological disease-modifying anti-rheumatic drugs (bDMARDs) have demonstrated anti-inflammatory effects in PsA. However, their comparative cardiovascular safety profiles remain unknown.

Objectives: Our objective was to assess the relative comparative risk of major adverse cardiovascular events (MACEs) of different classes of bDMARDs or apremilast for PsA.

Methods: This nationwide cohort study involved the administrative healthcare database of the French health insurance scheme covering approximately 67 million individuals linked to the hospital discharge database. All adults with PsA who were new users of bDMARDs/apremilast (neither in the year before the index date) during 2015-2019 were included. Patients with previous cardiovascular diseases were excluded. End of follow-up was December 31, 2019. The primary end point was an occurrence of MACE (acute myocardial infarction and ischaemic stroke) in a time-to-event analysis with propensity score-weighted Cox and Fine-Gray models (including age, sex, inflammatory diseases associated cardiovascular risk biomarkers and other comorbidities). To assess the sensitivity of the estimated weighted hazard ratio $(\mathrm{HRw})$ with respect to several possible models, we performed a per-protocol analysis, a conventional multivariate Cox model, an analysis using a larger definition of MACE, an analysis modifying the new-user definition (as those who had not filled a prescription for a bDMARDs or apremilast for 5 years before the index date) and an analysis modifying the treatment discontinuation definition.

Results: Between 2015 and 2019, we included 9,510 bDMARD new users (mean age $48.5 \pm 12.7$ years; $42 \%$ men), including 7,289 starting a TNF inhibitor, 1,058 an IL12/23 inhibitor and 1,163 an IL17 inhibitor, with 1,885 apremilast new users (mean age $54.0 \pm 12.5$ years; $44 \%$ men). MACEs occurred in $51(0.4 \%)$ patients (Figure 1). After propensity score weighting, the risk of MACEs was significantly greater with IL12/23 (HRw 2.0,95\%Cl 1.3-3.0) and IL17 (HRw 1.9, 95\% Cl 1.2 3.0) inhibitors than TNF inhibitors, with no significant increased risk with apremilast ( $\mathrm{HRw} 1.3,95 \% \mathrm{Cl} 0.8-2.2)$. Similar results were observed with the Fine-Gray competing-risks survival model. The sensitivity analyses results were consistent with those of the main analysis.

Conclusion: Analysis of a large national database revealed an overall small number of MACEs. Using robust methodology from the causal inference field, the risk of MACEs was greater for PsA new users of IL12/23 and IL17 versus TNF inhibitors. The risk of MACEs did not significantly differ between new users of apremilast and new users of TNF inhibitors.

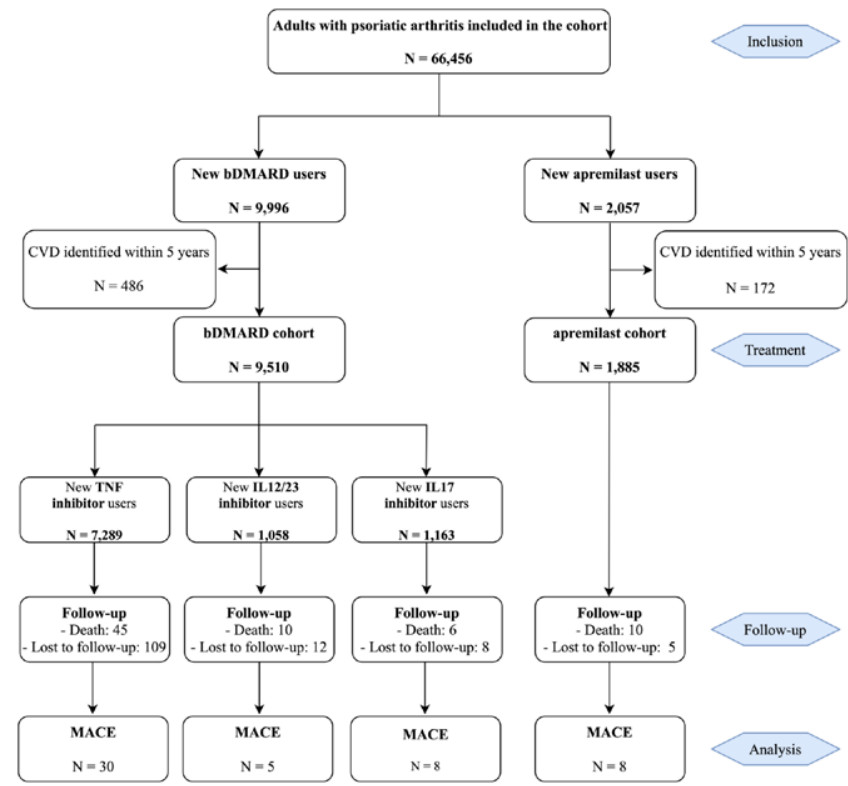

Figure 1. Flowchart for analytic approachData are n. bDMARD: biological disease-modifying antirheumatic drugs; CVD: cardiovascular disease; TNF: tumor necrosis factor; IL: interleukin; MACE: major adverse cardiac events.

Acknowledgements: $L$ Pina Vegas received a Master 2 grant from the French Society of Rheumatology (Bourse Master 2ème Année 2019)

Disclosure of Interests: Laura Pina Vegas: None declared, Philippe Le Corvoisier: None declared, Laetitia Penso: None declared, Muriel Paul: None declared, Emilie Sbidian: None declared, Pascal Claudepierre Speakers bureau: AbbVie, Janssen, Lilly, MSD, Novartis, Pfizer, Consultant of: Abbvie, Pfizer, RocheChugai, Bristol-Myers Squibb, MSD, UCB, Novartis, Janssen, Lilly, Celgene (consulting fees, less than 10,000 \$ each)., Employee of: Roche Chugai, Sanofi Aventis, Celgene, Pfizer, MSD, Novartis and BMS (investigator).

DOI: 10.1136/annrheumdis-2021-eular.287

\section{Rheumatoid arthritis - biological DMARDs}

\begin{tabular}{l|l}
\hline POS0202 & ANALYZING CORD BLOOD LEVELS OF TNF \\
INHIBITORS TO VALIDATE THE EULAR POINTS- \\
TO-CONSIDER FOR TNF INHIBITOR USE DURING \\
PREGNANCY
\end{tabular}

E. Kemper ${ }^{1,2}$, N. Ghalandari ${ }^{1,2}$, H. J. M. J. Crijns ${ }^{2}$, H. T. Smeele ${ }^{1}$, R. Dolhain ${ }^{1}$.

${ }^{1}$ Erasmus MC, Department of Rheumatology, Rotterdam, Netherlands;

${ }^{2}$ Medicines Evaluation Board, FT group 1, Utrecht, Netherlands 
Table 1. TNF inhibitor use during pregnancy and TNF inhibitor concentrations in mother's blood and cord blood.

\begin{tabular}{|c|c|c|c|c|}
\hline & Certolizumab pegol $(n=68)$ & Etanercept $(n=28)$ & Adalimumab $(n=24)$ & Infliximab $(n=13)$ \\
\hline Stop time point as recommended by EULAR & $\mathrm{N} / \mathrm{A}$ & GA $30-32$ & GA 20 & GA 20 \\
\hline Gestational age at time of stopping TNFi, median \pm IQR & $37.29(32.79-38.29)$ & $25.43(18.71-28.36)$ & $18.79(8.93-19.86)$ & $18.86(14.57-20.00)$ \\
\hline Measurable TNFi in cord blood, $\mathrm{n}(\%)$ & $4(5.9 \%)$ & $0(0 \%)$ & $12(50.0 \%)$ & $8(61.5 \%)$ \\
\hline Maternal concentration of TNFi in the 1st trimester, median \pm IQR $(\mu \mathrm{g} / \mathrm{ml})$ & $24.55(19-31)$ & $2.1(0.8-2.5)$ & $8.2(1.5-10)$ & $14(7.98-21)$ \\
\hline Maternal concentration of TNFi in the 2 nd trimester, median $\pm \mathrm{IQR}(\mu \mathrm{g} / \mathrm{ml})$ & $22.52(13-30.72)$ & $1.4(0.89-2.7)$ & $6(4.5-7.5)$ & $6.37(4.2-20)$ \\
\hline Maternal concentration of TNFi in the 3rd trimester, median \pm IQR $(\mu \mathrm{g} / \mathrm{ml})$ & $20.5(13-29.58)$ & $0.2(0.2-0.67)$ & $0.85(0.1-1.4)$ & $1.4(0.09-1.9)$ \\
\hline Concentration of TNFi in the cord blood if measurable, median $\pm \mathrm{IQR}(\mu \mathrm{g} / \mathrm{ml})$ & $0.25(0.15-1.3)$ & - $\quad-2$ & $0.45(0.15-0.65)$ & $0.4(0.12-1.15)$ \\
\hline
\end{tabular}

Background: Increasing evidence suggests that TNF inhibitors (TNFi) are safe to use during pregnancy ${ }^{1}$. A drawback of TNFi use during pregnancy is active transport across the placenta, which is affected by the structure of the $\mathrm{TNFi}^{1}$. The European League Against Rheumatism (EULAR) defined points to consider $(\mathrm{PtC})$ on the use of TNFi during pregnancy ${ }^{2}$ : to prevent placental transfer, etanercept should be discontinued at gestational age (GA) 30-32 weeks, and both adalimumab and infliximab should be discontinued at GA 20 weeks. Certolizumab pegol can be conditionally continued throughout pregnancy.

Objectives: The aim of this research is to validate the EULAR PtC by measuring the level of TNFi in cord blood.

Methods: Patients were derived from the PreCARA study, an ongoing prospective cohort study on inflammatory rheumatic diseases and pregnancy in the Netherlands. Patients were treated according to a treat-to-target approach, which included the use of TNFi. TNFi were, if possible, discontinued at recommended stop time points. Maternal blood samples were collected in each trimester. Cord blood was analyzed for the presence of certolizumab pegol, etanercept, adalimumab and infliximab. Levels of TNFi in the cord blood were compared between patients that stopped at the advised GA and patients who did not.

Results: Data from 111 patients with inflammatory rheumatic diseases were used for the current analysis. Most patients stopped treatment before the recommended GA (table 1). Certolizumab pegol $(n=68)$ was measured in a low number of cord blood samples (5.9\%) and in low concentrations (median, (IQR): $0.25 \mu \mathrm{g} / \mathrm{ml}(0.15-1.3))$. Etanercept was not detected in any cord blood samples $(n=28)$. Adalimumab $(n=24)$ and infliximab $(n=13)$ were measured more often in cord blood (in $50.0 \%$ and $61.5 \%$ of patients, respectively), this also was observed in patients that stopped before the recommended GA (in $47.7 \%$ for adalimumab and $60.0 \%$ for infliximab). However, the observed concentrations were low: the maximum observed concentrations in cord blood were $2.1 \mu \mathrm{g} / \mathrm{ml}$ (stopped at GA 19.4 weeks) for adalimumab and $4.5 \mu \mathrm{g} / \mathrm{ml}$ (stopped at GA 21.1 weeks) for infliximab.

Conclusion: Stopping TNFi around the GA recommended by the EULAR PtC resulted in no measurable levels or low concentrations of TNF inhibitor in the cord blood in a majority of patients.

\section{REFERENCES:}

[1] Smeele HTW, Dolhain RJEM. Current perspectives on fertility, pregnancy and childbirth in patients with Rheumatoid Arthritis. Semin Arthritis Rheum. 2019;49(3S):S32-S35. doi:10.1016/j.semarthrit.2019.09.010

[2] Götestam Skorpen C, Hoeltzenbein M, Tincani A, et al. The EULAR points to consider for use of antirheumatic drugs before pregnancy, and during pregnancy and lactation. Ann Rheum Dis. 2016;75(5):795-810. doi:10.1136/ annrheumdis-2015-208840

Disclosure of Interests: Erik Kemper: None declared, Nafise Ghalandari: None declared, Hubertina Johanna Maria Josephina Crijns: None declared, Hieronymus TW Smeele: None declared, Radboud Dolhain Speakers bureau: UCB, Roche, Abbvie, Genzyme, Novartis, Consultant of: Galapagos, Grant/research support from: UCB

DOI: 10.1136/annrheumdis-2021-eular.2452

\section{POS0204 AUTOANTIBODIES AND SYSTEMIC LUPUS ERYTHEMATOSUS INDUCED BY ANTI-TUMOUR NECROSIS FACTOR ALPHA THERAPY IN RHEUMATOID ARTHRITIS}

D. Santos Oliveira ${ }^{1,2}$, A. Martins ${ }^{1}$, F. R. Martins ${ }^{3}$, F. Oliveira Pinheiro ${ }^{1}$, M. Rato ${ }^{1}$, D. Fonseca ${ }^{4}$, B. M. Fernandes ${ }^{1}$, S. Garcia ${ }^{1}$, C. Vaz ${ }^{1,2,5}$, M. Bernardes ${ }^{1,5}$, L. Costa ${ }^{1} .{ }^{1}$ Centro Hospitalar Universitário de São João, Rheumatology Department, Porto, Portugal; ${ }^{2}$ Faculty of Medicine, University of Porto, Center for Health Technology and Services Research (CINTESIS), Porto, Portugal; ${ }^{3}$ Centro Hospitalar Universitário do Algarve, Rheumatology Department, Faro, Portugal; ${ }^{4}$ Centro Hospitalar Vila Nova de Gaia / Espinho, Rheumatology Department, Vila Nova de Gaia, Portugal; ${ }^{5}$ Faculty of Medicine, University of Porto, Department of Medicine, Porto, Portugal

Background: Anti-tumour necrosis factor alpha (anti-TNF- $\alpha$ ) therapy is commonly used to treat inflammatory conditions such as rheumatoid arthritis (RA). Autoantibodies namely antinuclear antibodies (ANA) induced by these treatments are well established. However, anti-TNF- $\alpha$-induced systemic lupus erythematosus (SLE) is rarely described and its incidence is yet unknown.

Objectives: This study aimed to determine the prevalence of ANA seroconversion and to characterize the development of SLE induced by anti-TNF- $\alpha$ therapy in patients with RA over time.

Methods: An observational retrospective cohort study was conducted with at least one year of follow-up. Patients with diagnosis of RA, according to American College of Rheumatology criteria (ACR), and registered on Rheumatic Diseases Portuguese Register (Reuma.pt) who started their first anti-TNF $\alpha$ between 2003 and 2019 were included. Patients with positive ANA (titer $\geq 100$ ) and/or positive double-strand DNA (dsDNA) antibodies and/or with a diagnosis of SLE at their first visit were excluded. Demographic, clinical and laboratory data were obtained by consulting Reuma.pt. As there are no recognized criteria for drug-induced SLE, the diagnosis of SLE induced by anti-TNF- $\alpha$ was considered if there is a temporal relationship between clinical manifestations and anti-TNF- $\alpha$-therapy, the presence of at least 1 serologic ACR criteria (ANA or anti-dsDNA) and at least 1 nonserologic ACR criteria (arthritis, serositis, hematologic disorder or malar rash) [1]. Continuous variables are presented with mean, standard deviation, median, quartile 1 and quartile 3. Categorical variables are presented with absolute and relative frequencies.

Results: A total of 211 patients (mean age of $49.9 \pm 10.9$ years old; $84.4 \%$ female) were included with a median follow-up time of 6 [3-14] years. We found a seroconversion rate for ANA of $75.4 \%(n=159)$ with median treatment duration of 31 [8.5-70.5] months. The most common titre was 1/100 with diffuse and speckled patterns. ANA seroconversion was higher for etanercept $(47.8 \%, n=76)$ than with adalimumab $(23.9 \%, n=38)$, infliximab $(13.8 \%, n=22)$ golimumab $(12.6 \%, n=20)$ or certolizumab $(1.9 \%, n=3)$. SLE induced by antiTNF- $\alpha$ occurred in two patients $(0.9 \%)$ with erosive and seropositive (rheumatoid factor and anti-citrullinated protein antibodies) RA previously treated with two conventional synthetic disease-modifying antirheumatic drugs, including methotrexate. The first patient, a female with 66 years old and 17 years of disease duration, developed SLE after 16 months of infliximab, with constitutional symptoms, abrupt worsening of polyarthritis, ANA titer of 1/320 diffuse pattern and positive dsDNA (248 UI/mL) antibodies. The second patient, a woman with 43 years old and 11 years of disease duration, developed SLE after 41 months of adalimumab with malar rash and ANA titer of 1/320 diffuse pattern, positive dsDNA (285 Ul/mL), positive anti-histone antibodies and hypocomplementemia. In these two cases, anti-TNF- $\alpha$ therapy was stopped and recovery was spontaneous without treatment. The first patient switched to adalimumab and the second switched to golimumab without recurrence of SLE for more than ten years.

Conclusion: We found a high rate of ANA seroconversion induced by antiTNF $\alpha$ therapy in patients with RA. However, similar to previous literature, only $0.9 \%$ of patients developed SLE with mild manifestations without major organ involvement. Although the drug with the highest ANA seroconversion rate was etanercept, those responsible for induced SLE were infliximab and adalimumab. Patients improved after discontinuation of therapy and tolerated an alternative anti-TNF- $\alpha$ drug without recurrence of induced SLE over time. Therefore, ANA and SLE induced by anti-TNF- $\alpha$ should be considered and reported in the follow-up of RA patients. Further research is needed to explore the impact of this adverse event on the outcomes of treatment over time.

\section{REFERENCES:}

[1] Hochberg MC. Arthritis Rheum. 1997;40(9):1725.

Disclosure of Interests: None declared

DOI: 10.1136/annrheumdis-2021-eular.3255

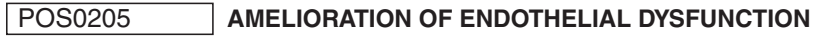 WITH JAK INHIBITION IN RHEUMATOID ARTHRITIS: JAK CV-RISK REDUCTION STUDY}

A. Syngle ${ }^{1}$, N. Garg ${ }^{2}$, K. Chauhan ${ }^{3} .{ }^{1}$ Healing Touch City Clinic, Chandigarh \& Fortis Multispecialty Hospital, Mohali, Cardio-Rheuma Division; Internal Medicine \& Rheumatology, Chandigarh, India; ${ }^{2}$ Chitkara College of Pharmacy, 